\title{
An Evidence-Based Model of Multidisciplinary Care for Patients and Families Affected by Classical Congenital Adrenal Hyperplasia due to 21-Hydroxylase Deficiency
}

\author{
Traci L. Schaeffer, ${ }^{1}$ Jeanie B. Tryggestad, ${ }^{1}$ Ashwini Mallappa, ${ }^{1}$ \\ Adam E. Hanna, ${ }^{1}$ Sowmya Krishnan, ${ }^{1}$ Steven D. Chernausek, ${ }^{1}$ Laura J. Chalmers, ${ }^{2}$ \\ William G. Reiner, ${ }^{2}$ Brad P. Kropp, ${ }^{2}$ and Amy B. Wisniewski ${ }^{1}$ \\ ${ }^{1}$ Pediatric Endocrinology, University of Oklahoma Health Sciences Center, Oklahoma City, OK 73104, USA \\ ${ }^{2}$ Pediatric Urology, University of Oklahoma Health Sciences Center, Oklahoma City, OK 73104, USA \\ Correspondence should be addressed to Amy B. Wisniewski, amy-wisniewski@ouhsc.edu \\ Received 18 November 2009; Accepted 19 January 2010 \\ Academic Editor: Peter Allen Lee
}

Copyright () 2010 Traci L. Schaeffer et al. This is an open access article distributed under the Creative Commons Attribution License, which permits unrestricted use, distribution, and reproduction in any medium, provided the original work is properly cited.

In 2002 a consensus statement pertaining to the management of classical congenital adrenal hyperplasia due to 21-hydroxylase deficiency was jointly produced by the Lawson Wilkins Pediatric Endocrine Society and the European Society of Pediatric Endocrinology. One of the recommendations of this consensus was that centers should maintain multidisciplinary teams for providing care and support to these patients and their families. However, the specifics for how this should be accomplished were not addressed in the original consensus statement. Here we interpret and translate the 2002 consensus statement recommendations into medical, surgical and mental health protocols. Additionally, we provide preliminary evidence that such protocols result in improved care and support for patients and families.

\section{Introduction}

Congenital adrenal hyperplasia $(\mathrm{CAH})$ is an autosomal recessive disorder due most commonly to a deficiency of 21 hydroxylase (21-OH) enzyme action that typically reduces cortisol and aldosterone secretion while simultaneously increasing androgen production [1]. Cortisone therapy to treat CAH was introduced in the early 1950s. Since that time, mortality from $\mathrm{CAH}$ has decreased as physicians and other healthcare professionals have gained knowledge and experience with the medical treatment of this disorder [2,3]. Despite these gains, optimal treatment of $\mathrm{CAH}$ remains elusive [4]. A consensus statement in 2002 by members of the Lawson Wilkins Pediatric Endocrine Society (LWPES) and the European Pediatric Endocrine Society (ESPE) attempted to "... consider the best practice, to formulate management guidelines, and to consider innovative therapies ..." related to 21-OH deficiency [4].

An important recommendation of the consensus was to organize and maintain a multidisciplinary team for providing medical, surgical, educational, mental health, and family support services to patients and their families [4]. Unfortunately, specific protocols for managing hormone levels during medical therapy, providing education about the pros and cons of feminizing genitoplasty, and how/when to introduce patients to mental health services and support groups were not offered [5]. The goals of this paper are to describe our multidisciplinary team approach to providing evidence-based care to patients and families affected by 21$\mathrm{OH}$ deficiency, and to assess the effectiveness of having such a clinic. Included is an interpretation and translation of the 2002 consensus statement recommendations into clinical practice, education, and social support protocols.

\section{Building Team Structure and Communication between Members}

The 2002 consensus statement recommends that "A wellorganized multidisciplinary team (including specialists in 
pediatric endocrinology, psychosocial services, pediatric surgery/urology, and genetics) is essential..." and "it is important that the coordinator of the team has an experience in the long-term care of the patient with $\mathrm{CAH}$ and provides a consistent message to patients [4]." The CAH team at the Children's Hospital of Oklahoma is comprised of professionals in the areas of nursing, newborn screening, pediatric endocrinology, adult endocrinology, pediatric urology, child psychiatry, and behavioral endocrinology. Genetic consultation is available on a case-by-case basis, but is not routinely obtained for all of our patients. Members of our team have conducted long-term studies of physical and mental health outcomes of patients affected by 21 $\mathrm{OH}$ deficiency as recommended by the 2002 consensus [4]. Results from these studies, in addition to others, were used to plan the clinic protocols and are included in the educational material provided to patients and their families. This has led to the inclusion of an adult endocrinologist to allow for transition services and support to individuals affected by $\mathrm{CAH}$ throughout the lifespan.

Our team is coordinated by a nurse employed by the state newborn screening program of Oklahoma. This nurse acts as the clinic coordinator and is the first point of contact to all families when a child is diagnosed with $21-\mathrm{OH}$ deficiency via the state newborn screening program. The clinic coordinator also initiates communication with affected families not identified by the state newborn screening program in the context of support groups. The clinic coordinator's contact information is provided on our website and on business cards that are distributed to patients and their families. The decision to have the newborn screening nurse act as the clinic coordinator was made to reduce confusion for families about whom to call when they need to reach a team member. All patients and parents are instructed to contact the clinic coordinator and she then contacts the appropriate team member for each case.

In addition to serving as the point-of-contact, the clinic coordinator also schedules joint clinic visits with pediatric urology, psychiatry, and pediatric endocrinology or adult endocrinology, depending upon patient needs. Furthermore, the clinic coordinator organizes a patient chart review for the team of providers at least 24 hours prior to clinic visits and also monthly journal club meetings to ensure that our team is developing and following evidence-based management protocols.

\section{Providing Team Communication to Patients and Families}

The CAH team meets with families of affected newborns at the bedside if they are at our home institution. If not, the family is invited to the Children's Hospital of Oklahoma for a family conference. This conference is open to family members and friends that parents wish to include. During these meetings education about $21-\mathrm{OH}$ deficiency is provided which includes handouts, national support group contact information, and our regional support group schedule.
The 2002 consensus statement indicates that "Monitoring may be accomplished based on physical and hormonal findings suggestive of excessive or inadequate steroid therapy [4]." Our team's protocol for a newborn identified through state screening begins as soon as newborn screening results are available, typically by 1 week of life. Initial education is provided at that time (please refer to Developing CAH Education for Patients, Families, and School Personnel). A medical treatment plan and schedule of monitoring, including the type and frequency of laboratory tests, bone age (BA) x-rays, and clinic visits by developmental stage is provided to all new patients and is also available on our website (see Table 1).

If children older than 3 years of age exhibit good hormonal control (indicated by a BA within normal limits after the age of 2 years, a growth velocity within normal limits, an androstenedione level within normal limits, and a 17-hydroxyprogesterone (17-OHP) level between 400$1200 \mathrm{ng} / \mathrm{dL}$ ) [1], then they will be scheduled for clinic visits every 4 months until epiphyseal fusion. For those who do not exhibit good control, more frequent visits are scheduled.

Communication with families of established patients includes a letter with upcoming appointment dates/times accompanied by a laboratory order sent 4 weeks prior to the next visit. Patients or parents are then called by the newborn screening nurse 48 hours prior to their appointment to ensure that appropriate laboratory studies were obtained. Patients who miss an appointment (our no-show rate is $<5 \%$ ) are called by the clinic coordinator within 1 week to reschedule and reiterate the importance of medical visits.

\section{Mental Health Services and Support Groups}

The 2002 consensus statement indicates "Psychological assessment and support of the patient and his/her family should be a routine component of the comprehensive care and management of these patients. Parents and/or patients should be offered the option of age- and sex-appropriate psychological counseling at the time of the initial diagnosis [4]." The majority (95\%) of girls and women with CAH develop a female gender identity regardless of their degree of genital masculinization at birth [6]. However, these women report poorer quality of life in addition to greater depression, anxiety, and suicidal thoughts than unaffected women [7]. Therefore, mental health services and peer support are needed even though gender dysphoria is rare. All patients and families in our clinic are introduced to the child psychiatrist member of our team and offered information about online and in-person support groups within the first 3 months of diagnosis. Patients and families meet with the child psychiatrist at least annually, and more frequent appointments are available as requested to discuss issues such as depression and anxiety.

Although gender identity consistently develops in a female-directed manner, gender role behaviors such as play and aggression are often masculinized in girls and women with CAH. Girls with CAH sometimes prefer toys and games [8], and exhibit levels of aggression [9], typically associated with boys. Additionally, women with null mutations of the 
TABLE 1: Typical multidisciplinary protocol for the CAH clinic at The Children's Hospital of Oklahoma.

\begin{tabular}{|c|c|c|c|c|c|c|c|}
\hline AGE & Objectives & $\begin{array}{c}\text { Visit } \\
\text { Schedule }\end{array}$ & Labs & Education & Urology & Psychiatry & $\begin{array}{c}\text { Support } \\
\text { Group }\end{array}$ \\
\hline 1st Month & $\begin{array}{l}\text { (i) Metabolic stability } \\
\text { (ii) Provide parents with } \\
\text { an understanding of } \\
\text { disease and treatment }\end{array}$ & $1,2 \& 4$ wks & $\begin{array}{l}\text { (i) CAH panel every } \\
\text { visit } \\
\text { (ii) Electrolytes every } \\
\text { visit }\end{array}$ & $\begin{array}{l}\text { (i) Meets with RN } \\
\text { each visit re: medical } \\
\text { regimen and stress } \\
\text { dosing }\end{array}$ & & & \\
\hline $\begin{array}{l}\text { Up to } \\
3 \text { years }\end{array}$ & $\begin{array}{l}\text { (i) Establish optimal } \\
\text { medical regimen } \\
\text { (ii) Feminizing surgery } \\
\text { as needed for females }\end{array}$ & Every 3 mos & $\begin{array}{l}\text { (i) CAH panel every } \\
\text { visit } \\
\text { (ii) Electrolytes } \\
\text { through 1st year } \\
\text { (iii) BA yearly starting } \\
\text { at age } 2\end{array}$ & $\begin{array}{l}\text { (i) Meets with RN } \\
\text { each visit re: medical } \\
\text { regimen } \\
\text { (ii) Meets with RN } \\
\text { annually re: stress } \\
\text { dosing, medic alert, } \\
\text { and CAH quiz }\end{array}$ & $\begin{array}{l}\text { Females see } \\
\text { urologist at } 3 \text {, } \\
6,12 \text { months }\end{array}$ & $\begin{array}{l}3,12 \text {, and } \\
24 \mathrm{mo}\end{array}$ & $\begin{array}{l}\text { Every } \\
4 \text { mos }\end{array}$ \\
\hline $\begin{array}{l}3 \mathrm{y} \text { to } \\
\text { adolescence }\end{array}$ & $\begin{array}{l}\text { (i) Adjust medical } \\
\text { regimen to maintain } \\
\text { normal growth and } \\
\text { health } \\
\text { (ii) Increase child's } \\
\text { understanding of } \\
\text { condition as appropriate } \\
\text { for age }\end{array}$ & Every 4 mos & $\begin{array}{l}\text { (i) CAH panel every } \\
\text { visit } \\
\text { (ii) BA yearly until } \\
\text { epiphyseal fusion }\end{array}$ & $\begin{array}{l}\text { (i) Meets with } \mathrm{RN} \\
\text { each visit re: medical } \\
\text { regimen } \\
\text { (ii) Meets with } \mathrm{RN} \\
\text { annually re: stress } \\
\text { dosing, medic alert, } \\
\text { and CAH quiz }\end{array}$ & $\begin{array}{l}\text { Females see } \\
\text { urologist } \\
\text { prior to } \\
\text { menarche }\end{array}$ & $\begin{array}{l}\text { Annually } \\
\text { or more } \\
\text { often as } \\
\text { needed }\end{array}$ & $\begin{array}{l}\text { Every } \\
4 \text { mos }\end{array}$ \\
\hline Adolescence & $\begin{array}{l}\text { (i) Adjust medical } \\
\text { regimen to maintain } \\
\text { normal growth, pubertal } \\
\text { development and } \\
\text { maintain health } \\
\text { (ii) Increase child's } \\
\text { understanding of } \\
\text { condition as appropriate } \\
\text { for age } \\
\text { (iii) Follow-up with } \\
\text { Urology for females }\end{array}$ & Every 4 mos & $\begin{array}{l}\text { (i) CAH panel every } \\
\text { visit } \\
\text { (ii) Annual testicular } \\
\text { exam for boys }\end{array}$ & $\begin{array}{l}\text { (i) Meets with } \mathrm{RN} \\
\text { each visit re: medical } \\
\text { regimen } \\
\text { (ii) Meets with RN } \\
\text { annually re: stress } \\
\text { dosing, medic alert, } \\
\text { and CAH quiz }\end{array}$ & $\begin{array}{l}\text { Females see } \\
\text { urologist } \\
\text { prior to } \\
\text { becoming } \\
\text { sexually } \\
\text { active }\end{array}$ & $\begin{array}{l}\text { Annually } \\
\text { or more } \\
\text { often as } \\
\text { needed }\end{array}$ & $\begin{array}{l}\text { Every } \\
4 \text { mos }\end{array}$ \\
\hline Adulthood & $\begin{array}{l}\text { (i) Transition to adult } \\
\text { medical care }\end{array}$ & Annually & CAH panel every visit & & As needed & $\begin{array}{l}\text { Annually } \\
\text { or more } \\
\text { often as } \\
\text { needed }\end{array}$ & $\begin{array}{l}\text { Every } \\
4 \text { mos }\end{array}$ \\
\hline
\end{tabular}

CYP21A2 gene (a marker of greater exposure to prenatal androgens) are more likely to choose masculine occupations and to exhibit interest in contact sports and motor vehicles despite having a female gender identity [10]. However, when retrospectively queried about their relative degrees of feminine/masculine behavior, most women with $\mathrm{CAH}$ report increased feminization and decreased masculinization with age [11]. While the majority of women affected by CAH report a heterosexual orientation, homosexuality, and bisexuality are more frequently reported than in unaffected females $[12,13]$. Similar to gender role, women with null mutations of the CYP21A2 gene are most likely to report sexual attraction to other females [10]. These are examples of nonpathologic behavioral development associated with $\mathrm{CAH}$ that some people prefer to discuss in peer support group environments rather than, or in addition to, clinical settings.

Cognition is a final aspect of behavioral health that is purported to be influenced by CAH. While some reports conclude that girls and women with $\mathrm{CAH}$ exhibit spatial processing abilities similar to males, most fail to find consistent differences between girls and women with $\mathrm{CAH}$ and unaffected females $[8,14]$. Finally, limited behavioral data from children at risk for $\mathrm{CAH}$ who were treated with dexamethasone prenatally indicate that verbal working memory [15], but not temperament [16], is affected by this therapy. As more children are exposed to dexamethasone prenatally, further long-term behavioral studies will be needed to guide clinical management of these children. Because the evidence does not support major cognitive differences due to $\mathrm{CAH}$, our clinical protocol does not routinely include neuropsychological assessment.

In contrast to the increased masculinization of overt gender role and sexual orientation with disease severity, patients' perceptions of the impact of their disease on their relationships with others are not associated with the degree of their 21-OH deficiency. Rather, mental health and educational support of patients and their families are better predictors of psychological adaptation [10]. In an effort to provide ongoing support and education to patients and families, local support groups for CAH are offered 
by the Children's Hospital of Oklahoma 3 times per year. These meetings are discussion-oriented and include fun activities designed to facilitate socialization among group members. The adult endocrinologist in our group attends these meetings so that younger patients and their families can interact with her prior to transitioning their care. Online and face-to-face peer support and education are also available via the CARES (http://www.caresfoundation.org/) and MAGIC (http:/www.magicfoundation.org/) Foundations.

\section{Developing CAH Education for Patients, Families, and School Personnel}

Initial education about 21-OH deficiency is provided by the clinic coordinator and includes a discussion of the hypothalamic-pituitary-adrenal (HPA) axis, negative feedback to maintain normal hormone production, and the underlying pathophysiology and genetics of $\mathrm{CAH}$. A folder containing general information about $\mathrm{CAH}$, Cortef, fludrocortisone, and national support groups is provided. Also provided in this folder is contact information for our clinic and emergency management. Oral and injectable stress dosing of glucocorticoids is emphasized in the initial education session, and a summary of this information is also provided in the folder. At the first education session, patients and parents are provided with a laminated emergency room (ER) card that includes contact information for the team's pediatric endocrinologists and contact information regarding days, nights and weekends, and instructions for intravenous (IV) fluid and glucocorticoid administration. All families are given a copy of Hsu and Rivkees' Congenital Adrenal Hyperplasia: A Parent's Guide [17] to take home as well. Parents are also provided with a "CAH emergency kit" containing a thermometer and everything needed to give an emergency intramuscular (IM) injection of hydrocortisone hemisuccinate (Solu-Cortef). Medical identification, for example, a Medic-Alert bracelet, is ordered by the clinic coordinator for all patients within the first 2-3 months of joining our clinic.

Continuing education about $\mathrm{CAH}$ is provided to patients and families by the clinic coordinator at each visit. Pathophysiology is reviewed and patient/parent questions are addressed if patients or parents have contacted our team for emergency management, that is discussed. A review of stress dosing (oral and injection) occurs at each visit, the importance of wearing medical identification is emphasized, and replacement emergency kits are provided as needed.

A quiz is administered to adult patients and parents of affected children to ensure that information about $\mathrm{CAH}$ has been successfully conveyed [18]. Those who do not show a complete understanding of this information are provided with additional education. Annually, older patients and parents are asked to demonstrate competency giving a Solu-Cortef injection. At that time families are also provided replacement ER cards as needed.

Educational material is provided to school personnel by the clinic coordinator when requested. This includes a medical letter describing the signs of adrenal insufficiency, how and when to administer a stress dose of glucocorticoid orally and intramuscularly, and how to contact the CAH team in emergency situations. Upon request the clinic coordinator travels to schools attended by patients to give a presentation on emergency management for CAH. This presentation lasts approximately 45 minutes and allows school staff to practice administering Solu-Cortef injections.

Children receive age-appropriate education about the endocrine system, CAH specifically, puberty, and why they visit our clinic. When a patient enters puberty, they receive information about the genetics of $\mathrm{CAH}$ and contraception. Boys receive information about testicular adrenal rest tumors and are instructed on how to perform testicular self-exams. Girls receive information about sexual function following genitoplasty (if such procedures have been performed), and are examined by a pediatric urologist at adolescence to determine the potential for peno-vaginal intercourse.

\section{Clinical Evaluation}

6.1. Growth. Linear growth rate throughout childhood, as well as final adult height, are important measures for assessing the adequacy of medical treatment [19]. Undertreatment with glucocorticoid results in hyperandrogenism and premature fusion of the epiphyses [20], while overtreatment impairs growth velocity [21]. The result of either sustained under- or over-treatment results in a final height that is less than that expected from an individual's genetic potential. Factors that have been identified that modulate growth velocity and final height include the age at diagnosis and the type and dose of glucocorticoid replacement used [19, 22-27]. Thus, careful height measurement is recommended for each clinic visit, including an interval height velocity calculation, to optimize medical management.

6.2. Weight. Monitoring weight is also recommended for patients with $\mathrm{CAH}$ [4]. When height, weight, and BMI were retrospectively analyzed at 1,5 , and 10 years of age, BMI significantly increased at years 5 and 10 in children with $\mathrm{CAH}$ [28]. An increased BMI puts children at risk for future complications such as polycystic ovarian syndrome (females), type 2 diabetes, and cardiovascular disease. Thus, we record weight and calculate BMI at each visit. Those patients with increased BMI are counseled on improving diet and physical activity.

6.3. Blood Pressure Monitoring. Prolonged exposure to mineralocorticoids is associated with elevated blood pressure and as a result routine monitoring of blood pressure is recommended in patients with $\mathrm{CAH}$ [4]. When ambulatory pressure is monitored, mean systolic values are significantly higher in children and adolescents compared to unaffected controls [29]. Blood pressure is monitored at every clinic visit as hypertension places people at risk for cardiovascular disease.

6.4. Laboratory Measures. Select laboratory parameters are used to guide adequacy of hormonal replacement. These are 
obtained every 3 months for the first 2 years of life and every 4 months thereafter. Circulating concentrations of 17 OHP, androstenedione, and testosterone (except for sexually mature males) are measured to judge the sufficiency of glucocorticoid replacement. Plasma renin activity and electrolytes are used to assess the replacement dose of mineralocorticoid [4]. Serum electrolytes are measured routinely during the first year of life only, as aberrant measures are not expected in individuals receiving proper medical treatment later in life.

Blood samples are obtained in the morning before the first medication dose to improve consistency of the 17OHP measurement as this varies greatly with respect to time of day and glucocorticoid dose [30]. We aim for levels of androstenedione, testosterone, and plasma renin activity to be in the normal range for prepubertal children, whereas modest elevations of 17-OHP are accepted. During adolescence, androstenedione and testosterone levels should rise in concert with the appearance of a normal puberty.

It is important to recognize that laboratory measures are more sensitive in the detection of under- compared to over-treatment. 17-OHP concentrations that are persistently suppressed below the target range of 400-1200 ng/dL probably indicate excessive glucocorticoid replacement [1], but need to be interpreted in light of other clinical parameters such as growth rate and BA progression. Testosterone levels that exceed those expected in prepubertal children certainly indicate inadequate glucocorticoid replacement [1]. Elevated renin indicates insufficient intake of either mineralocorticoid replacement or salt. It is essential to correct mineralocorticoid insufficiency as this may make the standard glucocorticoid dose less effective in controlling adrenocortical activity [31].

6.5. Bone Age. The utility of monitoring BA for assessing growth and predicting growth potential is undisputed [32]. BA is monitored annually in our patients, starting at the age of 2 years and stopping when epiphyseal fusion is complete. When clinically indicated, such as at the onset of puberty or a change in growth velocity is detected, BA may be measured as frequently as every 6 months. BA reports are read by an experienced radiologist as well as the pediatric endocrinologist who cares for each patient. Our aim is to achieve normal BA advancement, and thus growth, by optimizing glucocorticoid replacement for each patient.

6.6. Testicular Adrenal Rest Tumors. The prevalence of testicular adrenal rest tumors (TART) in males affected by $21-\mathrm{OH}$ deficiency varies greatly $(0-95 \%)$ across studies [33-35]. This variance is due to differences in patient age, disease severity, and medical management, as well as different methodologies employed for tumor detection. Though TART may be found prior to puberty by ultrasound, the clinical significance of this is uncertain. Therefore, our protocol for evaluation of TART includes annual testicular examination beginning at puberty. Abnormal findings revealed by testicular examination are subsequently evaluated by a scrotal ultrasound [36].

\section{Endocrine Management}

7.1. Glucocorticoid Dosing. The optimal glucocorticoid dose replaces deficient endogenous cortisol, prevents virilization, optimizes growth, and protects fertility [4]. The normal daily production rate of cortisol is approximately $6 \mathrm{mg} / \mathrm{m}^{2} /$ day; however, doses of 12 to $15 \mathrm{mg} / \mathrm{m}^{2} /$ day or higher are typically needed to adequately reduce androgen overproduction [37]. Recommended glucocorticoid replacement is with 10$15 \mathrm{mg} / \mathrm{m}^{2} /$ day of hydrocortisone divided into 3 daily doses, with doses as high as $25 \mathrm{mg} / \mathrm{m}^{2}$ during infancy [38]. Treatment with hydrocortisone, prednisone, or dexamethasone can result in normal growth if therapy is initiated before the BA advances beyond chronological age $[22,39]$. At the completion of linear growth, the consensus statement gives the option of changing to prednisolone $2-4 \mathrm{mg} / \mathrm{m}^{2}$ twice daily or dexamethasone $0.25-0.375 \mathrm{mg} / \mathrm{m}^{2}$ once daily [4]. Our clinic's protocol for glucocorticoid dosing states that children are started on Cortef tablets $10-20 \mathrm{mg} / \mathrm{m}^{2}$, administered in 3 doses approximately 8 hours apart with the largest dose given in the morning [40]. Dexamethasone is considered for patients who have finished growing or for whom compliance issues necessitate once-daily dosing. Overall, doses are adjusted based on values of 17-OHP, androstenedione, and testosterone along with BA and growth data.

7.2. Mineralocorticoid Dosing and Salt Supplementation. All patients are initially prescribed a daily dose of $0.1 \mathrm{mg}$ of fludrocortisone. This dose is then titrated based on plasma renin activity levels and blood pressure measurements [4]. For infants, electrolytes are also considered when titrating the mineralocorticoid replacement. All patients not exclusively fed table food are supplemented with sodium chloride, 2$3 \mathrm{~g} /$ day, distributed in breast milk or formula throughout the day. Parents are given a test tube marked with the amount of salt that needs to be supplemented daily. Different methods of salt supplementation techniques have been effective for our patients (e.g., medication pacifiers, adding small amounts of salt/salt water to each feeding).

7.3. Glucocorticoid Dosing and Emergency Management. For stress dosing, the 2002 consensus statement recommends that "...patients should be given increased doses of glucocorticoids during febrile illness ( $>101 \mathrm{~F}$ ), when vomiting or when unable to take oral feedings, after trauma, and before surgery" and "Stress dosing should be 2-3 times the maintenance glucocorticoid dose for patients able to take oral medications [4]." Patients in our clinic are instructed to take a triple dose of oral medication in the case of minor illness or injury, such as a fever exceeding $101^{\circ} \mathrm{F}$, vomiting once, sprain, or ear infection. They are also instructed to take a triple dose of medication for 2-3 days following a major stressor such as a broken bone or pneumonia. Parents can give oral stress doses without notifying our team until after the fact. The 2002 consensus statement recommends that "Guidelines for IV bolus and subsequent doses are as follows: for children younger than $3 \mathrm{yr}$ of age, $25 \mathrm{mg}$ followed by $25-30 \mathrm{mg} / \mathrm{d}$; for children $3-12 \mathrm{yr}$ of age, $50 \mathrm{mg}$ followed by $50-60 \mathrm{mg} / \mathrm{d}$; and for adolescents and adults, $100 \mathrm{mg}$ followed by 
$100 \mathrm{mg} / \mathrm{d}$ [4].” The use of home IM Solu-Cortef is advised for major illness or injury, such as severe trauma or dehydration. Parents are instructed to administer IM Solu-Cortef anytime their child cannot take pills by mouth, followed promptly by a visit to the ER if the situation is severe or persistent.

7.4. Delaying Pubertal Development. Central precocious puberty develops in children with $\mathrm{CAH}$ when adequate suppression of ACTH (and androgens) follows a period of chronic adrenal androgen overexposure due to inadequate cortisol replacement. For both sexes, advanced BA is a good predictor of which children are most likely to develop central precocious puberty [41]. The diagnosis of central precocious puberty is confirmed when GnRH stimulation testing shows a robust $\mathrm{LH}$ response that exceeds that of $\mathrm{FSH}$ and when accompanied by additional clinical and laboratory features of puberty. Girls may receive a baseline pelvic ultrasound to obtain uterine measurements and assess the presence or absence of an endometrial stripe prior to the initiation of treatment $[42,43]$. GnRH agonists (GnRHa) are effective at preventing further progression of the clinical signs of central precocious puberty when coupled with appropriate glucocorticoid and mineralocorticoid replacement [41]. Such treatment can be administered either as daily sc, monthly depot injections, or implants [44]. During GnRHa therapy monitoring of Tanner stages, height, and growth velocity should occur every 3-4 months. Therapy may be continued until the child reaches the chronological age when puberty is expected and either: (1) the BA and current height predict that a normal adult height can be reached, or (2) the growth velocity is so slow and the BA so far advanced that there is little to gain with continued treatment.

7.5. Adjunctive Therapies. The adult height of those with classical forms of CAH can be significantly compromised [19]. Adjunctive therapies have been proposed to improve final height including GnRHa to delay the onset of puberty beyond the normal age in order to extend the period of growth. Though modest effects have been reported [45], such treatment is considered experimental at this time [46].

Other adjunctive therapies considered for use in people affected by $\mathrm{CAH}$ include medications for limiting the effects of androgens and estrogens on virilization and bone maturation, respectively. For example, treating with flutamide (an antiandrogen) and testolactone (an aromatase inhibitor) allows for a more physiologic replacement dose of cortisol to be administered to patients without an acceleration of growth or untoward BA advancement [47]. Although encouraging, data on such treatment approaches are limited and thus these therapies are not part of our routine management of patients_-most of whom reach an adult height within the normal range despite having received solely conventional hormone replacement [24].

7.6. Bone Health. Chronic use of glucocorticoids both increases bone resorption and decreases bone formation $[48,49]$. A review of data reveals contradictory results of the potentially adverse effects of chronic glucocorticoid replacement on bone health in both children and adults with CAH. Several studies in adults reveal decreased bone mineral density (BMD) with treatment [50-53], while others report no effect $[54,55]$. Similarly, in young adults and children with $\mathrm{CAH}$ some studies fail to detect an effect of glucocorticoid replacement $[56,57]$ while others observe decreased BMD [58]. Overall, these data are limited by several factors including failure to match for race and age between those affected by $\mathrm{CAH}$ and controls, as well as the difficulty of interpreting bone densitometry data in children.

Observations of lower BMD, as well as increased occurrence of fractures, exist for women with $\mathrm{CAH}$ [59]. For younger patients our goal is to avoid over-suppression with glucocorticoids and emphasizing the importance of vitamin $\mathrm{D}$ and calcium intake. For older patients, a baseline dual energy X-ray absorptiometry (DXA) measure is ordered when epiphyseal fusion is complete.

\section{Limiting Adverse Responses to Genital Exam- inations and Medical Photography}

The 2002 consensus statement recommends that "The prior practice of frequent genital examinations in females should be abandoned [4]." The consensus advises that genital exams be performed only in light of evidence of poor medical compliance. This recommendation is in response to adverse patient reactions to medical photography and genital exams [60]. Residents and rotating medical students may be present during patient genital exams, with the permission of the child's parents, until the patient (female or male) is 2 years of age. Subsequently, only the endocrine and urology attending physicians and fellows perform genital exams on affected children, and every attempt is made to perform these examinations together to avoid frequent exposure. Medical photography, following informed consent of parents, may be done up to 1 year of age in the clinic. After that point, medical photography is only obtained when the patient is sedated following appropriate consent. In our clinic this standard is applied to both sexes.

\section{Surgical Management}

Females affected by $\mathrm{CAH}$ due to $21-\mathrm{OH}$ deficiency comprise the largest diagnostic group of individuals born with ambiguous genitalia. According to the 2002 consensus statement the goals of feminizing genitoplasty in affected girls and women are: (1) to create a female genital appearance, (2) to create unobstructed urinary emptying free of incontinence or infections, and (3) to allow for good adult sexual and reproductive function [4]. There are several types of surgical procedures for genital feminization; however, there are limited long-term outcome data regarding success rates for achieving desired results. Additionally, disagreement exists about the optimal timing for these procedures to be performed throughout development.

For parents and patients who choose feminizing genitoplasty, procedures can include clitoroplasty, labial reconstruction and vaginoplasty. Regarding clitoroplasty, total 
excisions were performed prior to the 1980s (see Table 2). More recently, the medical community has recognized that clitoroplasty that preserves the glans and neurovascular bundle of the clitoris will inevitably demonstrate improvement in long-term sexual function [61-66]. Concerning vaginoplasty, the type of procedure employed depends on the point of entry of the vagina into the urogenital sinus. In most of the studies reviewed (see Table 2) a Fortunoff posterior flap vaginoplasty was performed if the point of entry was low (Prader I-III) and a pull-through procedure was performed if the point of entry was high (Prader IV$\mathrm{V})$. A recent modification of pull-through vaginoplasty is partial urogenital sinus mobilization (PUM). Good cosmetic outcome is associated with this procedure; however, due to the fact that this is a recent modification functional outcome data are lacking at this time [67].

A review of feminizing genitoplasty outcome data published since 2000 reveals clinically relevant observations. First, clitoroplasty can, but does not always, lead to normal clitoral sensation and orgasmic potential even when the dorsal nerves are preserved and surgery is limited to a single procedure $[63,64,66,70]$. While procedures that preserve dorsal nerve function appear to offer a benefit over total excision [70], only a third of women who have received this type of procedure report sensitivity to temperature and vibration that is similar to unaffected women [66]. To optimize the likelihood of a satisfactory outcome of clitoroplasty, it is recommended that only experienced surgeons perform this surgery $[4,69]$. Finally, parents can be reassured that an affected girl's clitoris will appear smaller as she grows if adrenal androgen production is appropriately suppressed with glucocorticoid replacement. Thus, a clitoris that appears large in infancy might look normal in an adolescent even when clitoroplasty has not been performed.

A second conclusion from our review of surgical outcome data is that the size of the introitus, but not the length of the vagina, is often too small in women who have received a vaginoplasty $[64,68]$. Those who have received a vaginoplasty are more likely to report infrequent intercourse and difficulties with vaginal penetration compared to those who have not undergone this surgery $[63,66]$. Additionally, girls born with more severe genital masculinization are more likely to require multiple procedures to create a functioning vagina and less likely to engage in vaginal penetration than those born with a lesser degree of masculinization $[61,63,65]$.

These outcomes reveal some of the difficulties associated with feminizing genitoplasty. Despite these problems, it is unclear if such procedures should be abandoned in total. This is because comparisons between girls and women with $\mathrm{CAH}$ who received genitoplasty versus those who did not are confounded by the fact that those who do not receive surgery are typically less masculinized at birth. As poor cosmetic and sexual function outcomes are associated with greater genital masculinization at birth and different types of procedures employed [62-64], simple comparisons between these groups are problematic. Additionally, dissatisfaction with cosmetic appearance and function of the genitalia are reported even among women with $\mathrm{CAH}$ who did not receive genitoplasty [64]. Finally, early genitoplasty can result in a satisfactory cosmetic outcome when performed by experienced surgeons who function as members of an interdisciplinary team such as that described here [69]. It is currently not possible to know how representative women are those who oppose early surgery, and some patients report that infancy is the optimal time for such treatment $[62,64]$. Surgeons have compromised by stating that vaginoplasty can be delayed if it is the only procedure required for feminization of the genitalia; however, when other genital surgery is needed or when symptoms such as urinary tract infections are present, early vaginoplasty is indicated [71].

A female infant referred to The Children's Hospital of Oklahoma will receive a cystoscopy and vaginoscopy at approximately 3-6 months of age if these procedures have not already been performed. A pediatric urologist and child psychiatrist discuss the pros and cons of genitoplasty, based on current literature, with families and patients considering such procedures. In accordance with the 2002 consensus statement, it is recommended that genitoplasty be performed at around 12 months of age [4]. When the point of entry of the vagina into the urogenital sinus is low, a singlestage clitoroplasty/vaginoplasty may be performed. The goals of this surgery are to reduce the size of the phallus while preserving the glans and dorsal nerve fibers as well as to bring the vaginal orifice to the perineal surface while separating it from the urethral opening.

\section{Effectiveness of an Evidence-Based, Multidisciplinary Team Approach toward CAH}

A review of the clinical management of medical conditions such as CAH from 23 European countries reveals that most centers interviewed provide subspecialty support to patients and families including mental health services [72]. Thus, professionals are implementing the consensus statement recommendations in their clinical practice. In an attempt to quantify the effectiveness of our team's protocol, we analyzed data from 14 families who attended our clinic both prior to, and following, the implementation of our evidence-based, multidisciplinary approach toward treating 21-OH deficiency. Six outcomes were assessed-3 related to medical management and 3 related to mental health and peer support.

First, we investigated if the recommended laboratory tests were obtained for patients more consistently following the implementation of our protocol. Significantly more patients obtained laboratory tests recommended by the 2002 consensus statement after our team and protocol were in place $\left(X^{2}(1)=5.12, P<.05\right)$. Although not statistically significant, there was evidence for improvement in obtaining BA $\left(X^{2}(1)=3.0, P=.08\right)$ data according to the 2002 consensus recommendation [4]. No change was observed for obtaining unnecessary laboratory tests $(P>.05)$.

Concerning mental health and peer support, significantly more patients and parents met with a mental health provider 
TABLe 2: Review of cosmetic and functional outcome studies of feminizing genitoplasty in girls and women with congenital adrenal hyperplasia due to 2-hydroxylase deficiency conducted from 2000-present.

\begin{tabular}{llll}
\hline $\begin{array}{l}\text { Dependent } \\
\text { Measure }\end{array}$ & $\begin{array}{l}\text { Sample size; age } \\
\text { range }(y) \text { at } \\
\text { participation }\end{array}$ & $\begin{array}{l}\text { Earliest surgery dates; age } \\
\text { range }(y) \text { of earliest surgery }\end{array}$ & Summary \\
\hline $\begin{array}{l}\text { Cosmetic } \\
\text { appearance }\end{array}$ & & Reference \\
\hline & $\begin{array}{l}\text { 1970s-1980s; } 2.4-9.9 \\
\text { (i) combination of clitoral } \\
\text { excision and reduction as } \\
\text { well as fortunoff flap or } \\
\text { pull through vaginoplasty }\end{array}$ & $\begin{array}{l}\text { (i) participants }(n=6) \text { who } \\
\text { experienced vaginal stenosis } \\
\text { secondary to their vaginoplasty } \\
\text { were less satisfied than the } \\
\text { authors with the appearance of } \\
\text { their genitalia }\end{array}$ \\
\hline $21 ; 7.0-19.0$ & $\begin{array}{l}\text { 1970s-1980s; 0.8-10.4 } \\
\text { (i) majority received } \\
\text { clitoral reduction and } \\
\text { fortunoff vaginoplasty }\end{array}$ & $\begin{array}{l}\text { (i) 24\% had a "good" outcome as } \\
\text { determined by the authors } \\
\text { (ii) most required more than a } \\
\text { single-stage genitoplasty }\end{array}$ \\
\hline $2 ; 21.0-71.0$ & $\begin{array}{l}\text { 1950s-1990s; 0.3-20.0 } \\
\text { (i) majority received } \\
\text { clitoral excision and } \\
\text { fortunoff vaginoplasty }\end{array}$ & $\begin{array}{l}\text { (i) author ratings of the } \\
\text { appearance of the genitals were } \\
\text { better than self-ratings }\end{array}$ \\
\hline
\end{tabular}
fortunoff vaginoplasty

(i) Equally good cosmetic outcome for participants who had surgery prior to 2 years of

1980s-1990s; <2.0->2.0 (i) combination of clitoral $15 ; 12.0-25.0$ $35 ; 18.0-43.0$ $49 ; 18.0-63.0$ excision, reduction and vaginoplasty and vaginal pull-through recession as well as V-Y

1990s-2000s; 0.1-16.0

(i) all received partial urogenital sinus mobilization and clitoral resection with preservation of neuron-vascular bundle and glanular reloaction, half received glanular reduction 1950s-1990s; 0.5-18.0

(i) combination of clitoral excision and resection as well as fortunoff or pull-through vaginoplasty

age versus after 2

(ii) Better cosmetic outcome for planned one-stage surgery than planned multistage

(iii) Better cosmetic outcome when the procedures were performed at an institution and by a surgeon with expertise in DSD (i) $87.5 \%$ had a "good" outcome as determined by the authors

(i) majority had a "good" outcome as determined by the authors and self-report

(ii) mean genital surgeries $<2$ (i) majority of women receiving clitoral surgery rated their clitoral size as "normal" versus majority of women not receiving surgery rates their clitoris as "too big"

(ii) unsatisfactory appearance attributed to size/location of clitoris and scar tissue in women who had received genitoplasty (iii) mean genital surgeries $>2$ 
Table 2: Continued.

\begin{tabular}{|c|c|c|c|c|}
\hline $\begin{array}{l}\text { Dependent } \\
\text { Measure }\end{array}$ & $\begin{array}{l}\text { Sample size; age } \\
\text { range }(y) \text { at } \\
\text { participation }\end{array}$ & $\begin{array}{l}\text { Earliest surgery dates; age } \\
\text { range }(y) \text { of earliest surgery }\end{array}$ & Summary & Reference \\
\hline \multicolumn{5}{|c|}{ Sexual function } \\
\hline & $27 ; 14.0-33.0$ & $\begin{array}{l}\text { 1970s-1980s; } 2.4-9.9 \\
\text { (i) combination of clitoral } \\
\text { excision and reduction as } \\
\text { well as fortunoff flap or } \\
\text { pull through vaginoplasty }\end{array}$ & $\begin{array}{l}\text { (i) women born } \\
\text { with greater masculinization } \\
\text { of their genitalia (Prader } \\
\text { III or greater) are more likely } \\
\text { to develop intravaginal stenosis } \\
\text { if they received a single-stage } \\
\text { vaginoplasty prior to puberty } \\
\text { (ii) participants }(n=6 \text { ) who } \\
\text { experienced vaginal stenosis sec- } \\
\text { ondary to their vaginoplasty were } \\
\text { less satisfied with their degree of } \\
\text { vaginal opening than examiners }\end{array}$ & {$[61]$} \\
\hline & $23 ; 21.0-71.0$ & $\begin{array}{l}\text { 1950s-1990s; 0.3-20.0 } \\
\text { (i) majority received } \\
\text { clitoral excision and } \\
\text { fortunoff vaginoplasty }\end{array}$ & $\begin{array}{l}\text { (i) women born with greater } \\
\text { genital masculinization } \\
\text { (salt-losing or SL) reported } \\
\text { poorer sexual function than } \\
\text { those with less masculinization } \\
\text { (simple-virilizing or SV) } \\
\text { following genitoplasty } \\
\text { (ii) SL women had a shorter } \\
\text { vagina than SV women following } \\
\text { genitoplasty }\end{array}$ & {$[62]$} \\
\hline
\end{tabular}

genitoplasty

1960s-2000s;

infancy-puberty

$41 ; 16.0-46.0$

$35 ; 18.0-43.0$

(i) all received nerve reduction
1985-2000; 0.2-19.6

(i) combination of fortunoff flap, pull-through and vaginal replacement

(i) 1 in 6 women born with less masculinized genitalia who did not receive genitoplasty were unable to have sexual intercourse versus 3 in 29 women born with more masculinized genitalia who well as fortunoff or did receive genitoplasty pull-through vaginoplasty

1990s-2000s; 0.1-19.0 sparing ventral clitoral

1950s-1990s; 0.5-18.0

(i) combination of clitoral excision and resection as well as perineal or pull-through vaginoplasty (ii) women born with more masculinized genitalia were more likely to a 2-stage genitoplasty

(i) no large dorsal nerves visualized in excised erectile tissue following clitoral reduction

(i) women born with greater genital masculinization (Prader IV-V) prior to genitoplasty have fewer sex partners and fewer episodes of vaginal penetration than less masculinized women (Prader I-III) or controls (ii) Prader IV-V women experience more difficulties with pain, lubrication, and orgasm than Prader I-III women or controls

(i) $27 \%$ developed vaginal strictures, 5\% developed major complications including fistulas and diversion colitis (ii) the complication rate for fortunoff flap vaginoplasties performed in prepubertal patients was higher than that of flap procedures performed postpubertally 
TABle 2: Continued.

\begin{tabular}{|c|c|c|c|c|}
\hline \multirow[t]{2}{*}{$\begin{array}{l}\text { Dependent } \\
\text { Measure }\end{array}$} & $\begin{array}{l}\text { Sample size; age } \\
\text { range }(y) \text { at } \\
\text { participation }\end{array}$ & $\begin{array}{l}\text { Earliest surgery dates; age } \\
\text { range }(y) \text { of earliest surgery }\end{array}$ & Summary & Reference \\
\hline & $28 ; 17.0-39.0$ & $\begin{array}{l}\text { 1970s-2000s; } 4.0-<16.0 \\
\text { (i) combination of clitoral } \\
\text { excision and reduction; } \\
\text { type of vaginoplasty not } \\
\text { reported }\end{array}$ & $\begin{array}{l}\text { (i) CAH women who had } \\
\text { received genitoplasty had less } \\
\text { frequent intercourse and greater } \\
\text { penetration difficulty and } \\
\text { anorgasmia than CAH women } \\
\text { who had not received } \\
\text { genitoplasty }(n=4) \\
\text { (ii) CAH women who had } \\
\text { received genitoplasty were less } \\
\text { sensitive to temperature and } \\
\text { vibration following clitoral } \\
\text { stimulation than controls } \\
\text { (iii) Other measures of sexual } \\
\text { function and avoidance did not } \\
\text { differ between women with CAH } \\
\text { who had received genitoplasty } \\
\text { versus those that did not and } \\
\text { controls }\end{array}$ & {$[66]$} \\
\hline & $49 ; 18.0-63.0$ & $\begin{array}{l}\text { 1950s-2000s; 0.5-20.0 } \\
\text { (i) combination of clitoral } \\
\text { excision, recession, and } \\
\text { resection as well as simple } \\
\text { cleavage or dorsal flap } \\
\text { vaginoplasty }\end{array}$ & $\begin{array}{l}\text { (i) } 20.4 \% \text { women were } \\
\text { dissatisfied with their } \\
\text { genitoplasty } \\
\text { (ii) those who had received } \\
\text { clitoral excision or multiple } \\
\text { clitoral surgeries reported the } \\
\text { least clitoral sensitivity } \\
\text { (iii) } 45.6 \% \text { women reported the } \\
\text { vaginal introitus as "too small" } \\
\text { or "tight" whether they received } \\
\text { vaginoplasty or not }\end{array}$ & {$[64]$} \\
\hline
\end{tabular}

at least annually $\left(X^{2}(1)=4.09, P<.05\right)$ after our multidisciplinary team and protocol were implemented. Similarly, more families received structured education about $21-\mathrm{OH}$ deficiency $\left(X^{2}(1)=15.55, P<.0005\right)$ and participated in peer support groups $\left(X^{2}(1)=13.26, P<.0005\right)$ following our attempt to translate the 2002 consensus statement recommendations [4] into standard clinical practice.

The 2002 consensus statement recommends that “... the management of congenital adrenal hyperplasia (CAH) remains difficult, and clinical practice varies substantially throughout the world [4]." We have attempted to interpret and translate the 2002 consensus statement recommendations into an evidence-based protocol when possible. Additionally, we have shown that this protocol is effective at improving medical and mental health services to patients and their families. Future works is needed to determine the sustainability of such clinics, as well as their ability to improve long-term health outcomes and quality of life for patients.

\section{References}

[1] D. P. Merke and S. R. Bornstein, "Congenital adrenal hyperplasia,” The Lancet, vol. 365, no. 9477, pp. 2125-2136, 2005.
[2] R. J. Winter and G. J. Klingensmith, "Congenital adrenal hyperplasia: mortality experience," in Congenital Adrenal Hyperplasia, P. A. Lee, L. P. Plotnick, A. A. Kowarski, and C. J. Migeon's, Eds., University Park Press, Baltimore, Md, USA, 1977.

[3] S. D. Grosse and G. Van Vliet, "How many deaths can be prevented by newborn screening for congenital adrenal hyperplasia?" Hormone Research, vol. 67, no. 6, pp. 284-291, 2007.

[4] Joint LWPES/ESPE CAH Working Group, "Consensus statement on 21-hydroxylase deficiency from the Lawson Wilkins Pediatric Endocrine Society and the European Society for Paediatric Endocrinology," Journal of Clinical Endocrinology \& Metabolism, vol. 87, pp. 4048-4053, 2002.

[5] S. A. Rivkees, "Why the consensus for consensus?" Journal of Pediatric Endocrinology and Metabolism, vol. 21, no. 6, pp. 503-505, 2008.

[6] A. B. Dessens, F. M. E. Slijper, and S. L. S. Drop, "Gender dysphoria and gender change in chromosomal females with congenital adrenal hyperplasia," Archives of Sexual Behavior, vol. 34, no. 4, pp. 389-397, 2005.

[7] T. H. Johannsen, C. P. L. Ripa, E. L. Mortensen, and K. M. Main, "Quality of life in 70 women with disorders of sex development," European Journal of Endocrinology, vol. 155, no. 6, pp. 877-885, 2006. 
[8] M. Hines, "Prenatal testosterone and gender-related behaviour," European Journal of Endocrinology, vol. 155, no. 1, pp. S115-S121, 2006.

[9] V. Pasterski, P. Hindmarsh, M. Geffner, C. Brook, C. Brain, and M. Hines, "Increased aggression and activity level in 3- to 11-year-old girls with congenital adrenal hyperplasia (CAH)," Hormones and Behavior, vol. 52, no. 3, pp. 368-374, 2007.

[10] L. Frisén, A. Nordenström, H. Falhammar, et al., "Gender role behavior, sexuality, and psychosocial adaptation in women with congenital adrenal hyperplasia due to CYP21A2 deficiency," Journal of Clinical Endocrinology and Metabolism, vol. 94, no. 9, pp. 3432-3439, 2009.

[11] D. N. Long, A. B. Wisniewski, and C. J. Migeon, "Gender role across development in adult women with congenital adrenal hyperplasia due to 21-hydroxylase deficiency," Journal of Pediatric Endocrinology and Metabolism, vol. 17, no. 10, pp. 1367-1373, 2004.

[12] R. W. Dittmann, M. E. Kappes, and M. H. Kappes, "Sexual behavior in adolescent and adult females with congenital adrenal hyperplasia," Psychoneuroendocrinology, vol. 17, no. 23, pp. 153-170, 1992.

[13] H. F. L. Meyer-Bahlburg, C. Dolezal, S. W. Baker, and M. I. New, "Sexual orientation in women with classical or nonclassical congenital adrenal hyperplasia as a function of degree of prenatal androgen excess," Archives of Sexual Behavior, vol. 37, no. 1, pp. 85-99, 2008.

[14] M. A. Malouf, C. J. Migeon, K. A. Carson, L. Petrucci, and A. B. Wisniewski, "Cognitive outcome in adult women affected by congenital adrenal hyperplasia due to 21-hydroxylase deficiency," Hormone Research, vol. 65, no. 3, pp. 142-150, 2006.

[15] T. Hirvikoski, A. Nordenström, T. Lindholm, et al., "Cognitive functions in children at risk for congenital adrenal hyperplasia treated prenatally with dexamethasone," Journal of Clinical Endocrinology and Metabolism, vol. 92, no. 2, pp. 542-548, 2007.

[16] T. Hirvikoski, A. Nordenström, T. Lindholm, F. Lindblad, E. M. Ritzén, and S. Lajic, "Long-term follow-up of prenatally treated children at risk for congenital adrenal hyperplasia: does dexamethasone cause behavioural problems?" European Journal of Endocrinology, vol. 159, no. 3, pp. 309-316, 2008.

[17] C. Y. Hsu and S. A. Rivkees, Congenital Adrenal Hyperplasia: A Parent's Guide, Author House, Bloomington, Ind, USA, 2005.

[18] J. King, I. Mitchelhill, and M. J. Fisher, "Development of the congenital adrenal hyperplasia knowledge assessment questionnaire (CAHKAQ)," Journal of Clinical Nursing, vol. 17, no. 13, pp. 1689-1696, 2008.

[19] E. A. Eugster, L. A. DiMeglio, J. C. Wright, G. R. Freidenberg, R. Seshadri, and O. H. Pescovitz, "Height outcome in congenital adrenal hyperplasia caused by 21-hydroxylase deficiency: a meta-analysis," Journal of Pediatrics, vol. 138, no. 1, pp. 26-32, 2001.

[20] C. Demirci and S. F. Witchel, "Congenital adrenal hyperplasia," Dermatologic Therapy, vol. 21, no. 5, pp. 340-353, 2008.

[21] J. Jaaskelainen and R. Voutilainen, "Growth of patients with 21-hydroxylase deficiency: an analysis of the factors influencing adult height," Pediatric Research, vol. 41, no. 1, pp. 30-33, 1997.

[22] S. A. Rivkees and J. D. Crawford, "Dexamethasone treatment of virilizing congenital adrenal hyperplasia: the ability to achieve normal growth," Pediatrics, vol. 106, no. 4, pp. 767$773,2000$.

[23] H. J. Van der Kamp, B. J. Otten, N. Buitenweg, et al., "Longitudinal analysis of growth and puberty in 21-hydroxylase deficiency patients," Archives of Disease in Childhood, vol. 87, no. 2, pp. 139-144, 2002.

[24] W. Bonfig, S. Bechtold, H. Schmidt, D. Knorr, and H. P. Schwarz, "Reduced final height outcome in congenital adrenal hyperplasia under prednisone treatment: deceleration of growth velocity during puberty," Journal of Clinical Endocrinology and Metabolism, vol. 92, no. 5, pp. 1635-1639, 2007.

[25] S. Appan, P. C. Hindmarsh, and C. G. D. Brook, "Monitoring treatment in congenital adrenal hyperplasia," Archives of Disease in Childhood, vol. 64, no. 9, pp. 1235-1239, 1989.

[26] I. Manoli, Ch. Kanaka-Gantenbein, A. Voutetakis, M. ManiatiChristidi, and C. Dacou-Voutetakis, "Early growth, pubertal development, body mass index and final height of patients with congenital adrenal hyperplasia: factors influencing the outcome," Clinical Endocrinology, vol. 57, no. 5, pp. 669-676, 2002.

[27] W. Bonfig, S. B. D. Pozza, H. Schmidt, P. Pagel, D. Knorr, and H. P. Schwarz, "Hydrocortisone dosing during puberty in patients with classical congenital adrenal hyperplasia: an evidence-based recommendation," Journal of Clinical Endocrinology and Metabolism, vol. 94, no. 10, pp. 3882-3888, 2009.

[28] R. E. Cornean, P. C. Hindmarsh, and C. G. D. Brook, "Obesity in 21-hydroxylase deficient patients," Archives of Disease in Childhood, vol. 78, no. 3, pp. 261-263, 1998.

[29] E. F. Roche, E. Charmandari, M. T. Dattani, and P. C. Hindmarsh, "Blood pressure in children and adolescents with congenital adrenal hyperplasia (21-hydroxylase deficiency): a preliminary report," Clinical Endocrinology, vol. 58, no. 5, pp. 589-596, 2003.

[30] E. Charmandari, D. R. Matthews, A. Johnston, C. G. D. Brook, and P. C. Hindmarsh, "Serum cortisol and 17hydroxyprogesterone interrelation in classic 21-hydroxylase deficiency: is current replacement therapy satisfactory?" Journal of Clinical Endocrinology and Metabolism, vol. 86, no. 10, pp. 4679-4685, 2001.

[31] M. Jansen, J. M. Wit, and J. L. van den Brande, "Reinstitution of mineralocorticoid therapy in congenital adrenal hyperplasia," Acta Paediatrica Scandinavica, vol. 70, no. 2, pp. 229-233, 1981.

[32] F. R. Kaufman and J. P. Sy, "Regular monitoring of bone age is useful in children treated with growth hormone," Pediatrics, vol. 104, no. 4, pp. 1039-1042, 1999.

[33] N. M. M. L. Stikkelbroeck, B. J. Otten, A. Pasic, et al., "High prevalence of testicular adrenal rest tumors, impaired spermatogenesis, and Leydig cell failure in adolescent and adult males with congenital adrenal hyperplasia," Journal of Clinical Endocrinology and Metabolism, vol. 86, no. 12, pp. 5721-5728, 2001.

[34] H. L. Claahsen-van der Grinten, F. C. G. J. Sweep, J. G. Blickman, A. R. M. M. Hermus, and B. J. Otten, "Prevalence of testicular adrenal rest tumors in male children with congenital adrenal hyperplasia due to 21-hydroxylase deficiency," European Journal of Endocrinology, vol. 157, no. 3, pp. 339344, 2007.

[35] A. Martinez-Aguayo, A. Rocha, N. Rojas, et al., "Testicular adrenal rest tumors and Leydig and Sertoli cell function in boys with classical congenital adrenal hyperplasia," Journal of Clinical Endocrinology and Metabolism, vol. 92, no. 12, pp. 4583-4589, 2007.

[36] N. A. Avila, T. S. Shawker, J. V. Jones, G. B. Cutler Jr., and D. P. Merke, "Testicular adrenal rest tissue in congenital 
adrenal hyperplasia: serial sonographic and clinical findings," American Journal of Roentgenology, vol. 172, no. 5, pp. 1235$1238,1999$.

[37] D. Merke and M. Kabbani, "Congenital adrenal hyperplasia: epidemiology, management and practical drug treatment," Paediatric Drugs, vol. 3, no. 8, pp. 599-611, 2001.

[38] D. P. Merke, D. Cho, K. A. Calis, M. F. Keil, and G. P. Chrousos, "Hydrocortisone suspension and hydrocortisone tablets are not bioequivalent in the treatment of children with congenital adrenal hyperplasia," Journal of Clinical Endocrinology and Metabolism, vol. 86, no. 1, pp. 441-445, 2001.

[39] V. V. Khadilkar, A. V. Khadilkar, and G. B. Maskati, "Impact of availability of oral hydrocortisone on growth of children with CAH," Indian Journal of Pediatrics, vol. 72, no. 4, pp. 301-303, 2005.

[40] E. Charmandari, A. Johnston, C. G. D. Brook, and P. C. Hindmarsh, "Bioavailability of oral hydrocortisone in patients with congenital adrenal hyperplasia due to 21-hydroxylase deficiency," Journal of Endocrinology, vol. 169, no. 1, pp. 6570, 2001.

[41] O. H. Pescovitz, F. Cassorla, F. Comite, D. L. Loriaux, and G. B. Cutler Jr., "LHRH analog treatment of central precocious puberty complicating congenital adrenal hyperplasia," Annals of the New York Academy of Sciences, vol. 458, pp. 174-181, 1985.

[42] L. de Vries, G. Horev, M. Schwartz, and M. Phillip, "Ultrasonographic and clinical parameters for early differentiation between precocious puberty and premature thelarche," European Journal of Endocrinology, vol. 154, no. 6, pp. 891-898, 2006.

[43] H. P. Haber, H. A. Wollmann, and M. B. Ranke, "Pelvic ultrasonography: early differentiation between isolated premature thelarche and central precocious puberty," European Journal of Pediatrics, vol. 154, no. 3, pp. 182-186, 1995.

[44] C. Dacou-Voutetakis and N. Karidis, "Congenital adrenal hyperplasia complicated by central precocious puberty: treatment with LHRH-agonist analogue," Annals of the New York Academy of Sciences, vol. 687, pp. 250-254, 1993.

[45] K. Lin-Su, M. G. Vogiatzi, I. Marshall, et al., "Treatment with growth hormone and luteinizing hormone releasing hormone analog improves final adult height in children with congenital adrenal hyperplasia," Journal of Clinical Endocrinology and Metabolism, vol. 90, no. 6, pp. 3318-3325, 2005.

[46] J.-C. Carel, E. A. Eugster, A. Rogol, L. Ghizzoni, and M. R. Palmert, "Consensus statement on the use of gonadotropinreleasing hormone analogs in children," Pediatrics, vol. 123, no. 4, pp. e752-e762, 2009.

[47] D. P. Merke, M. F. Keil, J. V. Jones, J. Fields, S. Hill, and G. B. Cutler Jr., "Flutamide, testolactone, and reduced hydrocortisone dose maintain normal growth velocity and bone maturation despite elevated androgen levels in children with congenital adrenal hyperplasia," Journal of Clinical Endocrinology and Metabolism, vol. 85, no. 3, pp. 1114-1120, 2000.

[48] E. Canalis, J. P. Bilezikian, A. Angeli, and A. Giustina, "Perspectives on glucocorticoid-induced osteoporosis," Bone, vol. 34, no. 4, pp. 593-598, 2004.

[49] M.-A. Valero, M. Leon, M. P. Ruiz Valdepenas, et al., "Bone density and turnover in Addison's disease: effect of glucocorticoid treatment," Bone \& Mineral, vol. 26, no. 1, pp. 9-17, 1994.

[50] Z. Chakhtoura, A. Bachelot, D. Samara-Boustani, et al., "Impact of total cumulative glucocorticoid dose on bone mineral density in patients with 21-hydroxylase deficiency," European Journal of Endocrinology, vol. 158, no. 6, pp. 879$887,2008$.

[51] K. Hagenfeldt, E. M. Ritzen, H. Ringertz, J. Helleday, and K. Carlstrom, "Bone mass and body composition of adult women with congenital virilizing 21-hydroxylase deficiency after glucocorticoid treatment since infancy," European Journal of Endocrinology, vol. 143, no. 5, pp. 667-671, 2000.

[52] J. A. King, A. B. Wisniewski, B. J. Bankowski, K. A. Carson, H. A. Zacur, and C. J. Migeon, "Long-term corticosteroid replacement and bone mineral density in adult women with classical congenital adrenal hyperplasia," Journal of Clinical Endocrinology and Metabolism, vol. 91, no. 3, pp. 865-869, 2006.

[53] C. Paganini, G. Radetti, C. Livieri, V. Braga, D. Migliavacca, and S. Adami, "Height, bone mineral density and bone markers in congenital adrenal hyperplasia," Hormone Research, vol. 54, no. 4, pp. 164-168, 2000.

[54] F. J. Cameron, B. Kaymakci, E. A. Byrt, P. R. Ebeling, G. L. Warne, and J. D. Wark, "Bone mineral density and body composition in congenital adrenal hyperplasia," Journal of Clinical Endocrinology and Metabolism, vol. 80, no. 7, pp. 2238-2243, 1995.

[55] N. M. M. L. Stikkelbroeck, W. J. G. Oyen, G.-J. van der Wilt, A. R. M. M. Hermus, and B. J. Otten, "Normal bone mineral density and lean body mass, but increased fat mass, in young adult patients with congenital adrenal hyperplasia," Journal of Clinical Endocrinology and Metabolism, vol. 88, no. 3, pp. 1036-1042, 2003.

[56] M. Gussinye, A. Carrascosa, N. Potau, et al., "Bone mineral density in prepubertal and in adolescent and young adult patients with the salt-wasting form of congenital adrenal hyperplasia," Pediatrics, vol. 100, no. 4, pp. 671-674, 1997.

[57] R. Girgis and J. S. D. Winter, "The effects of glucocorticoid replacement therapy on growth, bone mineral density, and bone turnover markers in children with congenital adrenal hyperplasia," Journal of Clinical Endocrinology and Metabolism, vol. 82, no. 12, pp. 3926-3929, 1997.

[58] M. Sciannamblo, G. Russo, D. Cuccato, G. Chiumello, and S. Mora, "Reduced bone mineral density and increased bone metabolism rate in young adult patients with 21-hydroxylase deficiency," Journal of Clinical Endocrinology and Metabolism, vol. 91, no. 11, pp. 4453-4458, 2006.

[59] H. Falhammar, H. Filipsson, G. Holmdahl, et al., "Fractures and bone mineral density in adult women with 21-hydroxylase deficiency," Journal of Clinical Endocrinology and Metabolism, vol. 92, no. 12, pp. 4643-4649, 2007.

[60] S. Creighton, J. Alderson, S. Brown, and C. L. Minto, "Medical photography: ethics, consent and the intersex patient," The Journal of Urology, vol. 169, no. 4, p. 1606, 2003.

[61] S. Krege, K. H. Walz, B. P. Hauffa, I. Körner, and H. Rüben, "Long-term follow-up of female patients with congenital adrenal hyperplasia from 21-hydroxylase deficiency, with special emphasis on the results of vaginoplasty," $B J U$ International, vol. 86, no. 3, pp. 253-259, 2000.

[62] A. B. Wisniewski, C. J. Migeon, M. A. Malouf, and J. P. Gearhart, "Psychosexual outcome in women affected by congenital adrenal hyperplasia due to 21-hydroxylase deficiency," The Journal of Urology, vol. 171, no. 6, pp. 2497-2501, 2004.

[63] F. Gastaud, C. Bouvattier, L. Duranteau, et al., "Impaired sexual and reproductive outcomes in women with classical forms of congenital adrenal hyperplasia," Journal of Clinical Endocrinology and Metabolism, vol. 92, no. 4, pp. 1391-1396, 2007. 
[64] A. Nordenskjöld, G. Holmdahl, L. Frisén, et al., “Type of mutation and surgical procedure affect long-term quality of life for women with congenital adrenal hyperplasia," Journal of Clinical Endocrinology and Metabolism, vol. 93, no. 2, pp. 380386, 2008.

[65] W. Hoepffner, K. Rothe, and J. Bennek, "Feminizing reconstructive surgery for ambiguous genitalia: the Leipzig experience," The Journal of Urology, vol. 175, no. 3, pp. 981-984, 2006.

[66] N. S. Crouch, L. M. Liao, C. R. Woodhouse, G. S. Conway, and S. M. Creighton, "Sexual function and genital sensitivity following feminizing genitoplasty for congenital adrenal hyperplasia," The Journal of Urology, vol. 179, no. 2, pp. 634638, 2008.

[67] L. H. P. Braga, A. J. Lorenzo, E. S. Tatsuo, I. N. Silva, and J. L. Pippi Salle, "Prospective evaluation of feminizing genitoplasty using partial urogenital sinus mobilization for congenital adrenal hyperplasia," The Journal of Urology, vol. 176, no. 5, pp. 2199-2204, 2006.

[68] S. M. Creighton, C. L. Minto, and S. J. Steele, "Objective cosmetic and anatomical outcomes at adolescence of feminising surgery for ambiguous genitalia done in childhood," The Lancet, vol. 358, no. 9276, pp. 124-125, 2001.

[69] W. L. Lean, A. Deshpande, J. Hutson, and S. R. Grover, "Cosmetic and anatomic outcomes after feminizing surgery for ambiguous genitalia," Journal of Pediatric Surgery, vol. 40, no. 12, pp. 1856-1860, 2005.

[70] D. P. Poppas, A. A. Hochsztein, R. N. Baergen, E. Loyd, J. Chen, and D. Felsen, "Nerve sparing ventral clitoroplasty preserves dorsal nerves in congenital adrenal hyperplasia," The Journal of Urology, vol. 178, pp. 1802-1806, 2007.

[71] B. Burgu, P. G. Duffy, P. Cuckow, P. Ransley, and D. T. Wilcox, "Long-term outcome of vaginal reconstruction: comparing techniques and timing," Journal of Pediatric Urology, vol. 3, no. 4, pp. 316-320, 2007.

[72] V. Pasterski, P. Prentice, and I. Hughes, "Consequences of the Chicago consensus on disorders of sex development (DSD): current practices in Europe," Archives of Disease in Childhood. In press. 